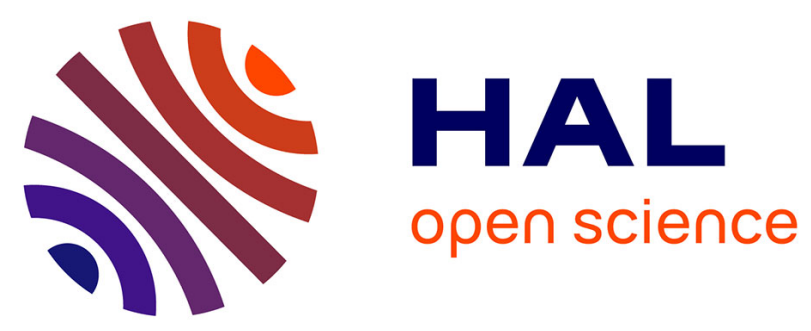

\title{
Variations of the main nighttime ionospheric density anomalies observed by DEMETER during the descending phase of solar cycle 23
}

\author{
Rui Yan, Michel Parrot, Jean-Louis Pinçon
}

\section{- To cite this version:}

Rui Yan, Michel Parrot, Jean-Louis Pinçon. Variations of the main nighttime ionospheric density anomalies observed by DEMETER during the descending phase of solar cycle 23. Journal of Atmospheric and Solar-Terrestrial Physics, 2018, 178, pp.66 - 73. 10.1016/j.jastp.2018.06.003 . insu01820396

\section{HAL Id: insu-01820396 \\ https://hal-insu.archives-ouvertes.fr/insu-01820396}

Submitted on 1 Apr 2021

HAL is a multi-disciplinary open access archive for the deposit and dissemination of scientific research documents, whether they are published or not. The documents may come from teaching and research institutions in France or abroad, or from public or private research centers.
L'archive ouverte pluridisciplinaire HAL, est destinée au dépôt et à la diffusion de documents scientifiques de niveau recherche, publiés ou non, émanant des établissements d'enseignement et de recherche français ou étrangers, des laboratoires publics ou privés.

\section{()ㅜ) $\Theta$}

Distributed under a Creative Commons Attribution - NoDerivatives| 4.0 International 
Variations of the main nighttime ionospheric density anomalies observed by DEMETER during the descending phase of solar cycle 23

Rui Yan ${ }^{1,2,3}$, Michel Parrot $^{1}$, and Jean-Louis Pinçon ${ }^{1}$

${ }^{1}$ Université d'Orléans, LPC2E/CNRS, Orléans, France

${ }^{2}$ Institute of Crustal Dynamics, China Earthquake Administration, Beijing, China

${ }^{3}$ Beijing Engineering Research Center of Earthquake Observation, Beijing, China

Correspondance to: M. Parrot (mparrot@cnrs-orleans.fr) LPC2E/CNRS, 3A Avenue de la Recherche Scientifique, 45045 Orléans cedex 02, France

Keywords : ionospheric anomalies; ion density; solar cycle 23

Abstract: This paper is related to analysis of the Weddell Sea Anomaly (WSA) and the Mid-latitude Summer Nighttime Anomaly (MSNA) observed by the low altitude satellite DEMETER during nighttime between 2004 and 2010. This time interval corresponds to the decrease of the solar cycle 23 which was unusually long. It appears that if these two anomalies have a peak in local summer (December in the Southern hemisphere for the WSA, June in the Northern hemisphere for the MSNA). The anomalies are also observed during the months around December and June with a decreased intensity. But at the end of the solar cycle 23 the summer peaks dramatically decrease and even relatively more quickly than the solar index F10.7. This phenomenon is much more significant for the WSA. It is shown that the mechanism producing the two anomalies (thermospheric neutral winds and magnetic declination effects) is strengthened by the solar ionization which is active during the night above the WSA and the MSNA areas. But at solar minimum, this mechanism is weakened. These results are valid at the satellite altitude $(660 \mathrm{~km})$ and may vary at lower altitudes.

\section{Introduction}

This paper is devoted to the analysis of the ion density observed by DEMETER at the descending phase of the solar cycle 23 at the location of important ionospheric anomalies: the Weddell Sea Anomaly (WSA) and the Mid-latitude Summer Nighttime Anomaly (MSNA).

The WSA was first discovered by an ionospheric sounder at Halley Bay by Bellchambers and Piggott (1958) who observed unusual ionospheric electron density enhancements during local summer nighttime, even higher than that of daytime. A similar behavior was registered in the Northern Hemisphere during the local summer. Enhanced nighttime density was identified over the northeast Asian region and the northern Atlantic Ocean. The northern hemispheric analogy of the WSA was named as the MSNA.

Later on with the satellites and the TEC measurement a lot of work has been done to study these anomalies and to understand the mechanism which produces them. TOPEX/Poseidon has been used by Horvath and Essex (2003), FORMOSAT-3/COSMIC by Burns et al. (2008), Lin et al. (2009, 2010), and DMSP by Horvath and Lovell (2009), to show that the area of the WSA is much larger than it was initially shown. He et al. (2009) used the FORMOSAT-3 mission during two years (from day of year (DOY) 121, 2006 to DOY 213, 2008) to generally investigate the nighttime ionospheric anomalies. In their study, all mid-latitude enhancements, appearing in the longitude sectors where the dip equator shifts toward the pole in both hemispheres, are considered as a Weddell Sea Anomaly. They surveyed the evolution of $\mathrm{F} 2$ peak parameters ( $\mathrm{NmF} 2$ and $\mathrm{hmF} 2$ ) as well as their longitudinal and seasonal variability in these regions. Jee et al. (2009) have studied the seasonal and solar activity variations of the WSA with TOPEX total electron content (TEC) measurements between 
1992 and 2005. They said that the TOPEX TEC maps display longitudinal variations for a given local time and that the WSA appears only in summer when F10.7 is low, but it appears in all seasons (except in winter) when F10.7 is high. In-situ measurements performed by the satellites CHAMP and GRACE during the years 2000-2009 have been used by Lühr and Xiong (2010) to compare the electron density with the predictions of the International Reference Ionosphere (IRI-2007) model. They concluded that, during the end of the solar cycle 23, this model overestimates the electron density mainly at low latitudes during daytime hours and, consequently, the equatorial ion fountain effect. Chang et al. (2015) studied local time and spatial variations of the WSA with Formosat-3 between 2007 and 2012 considering possible tidal and stationary planetary waves effect.

DEMETER has been also widely used to investigate these anomalies. Li et al. (2011) have studied electron density and temperature measured by DEMETER under different magnetic activities but only from 17 November 2004 to 30 November 2005. They have shown that whatever is this magnetic activity, quiet or strong, the WSA and the MSNA are present. Zhang (2014) has performed an electron density comparison with the IRI model to underline the discrepancy during this low solar activity. Zhang et al. (2014a) have plotted maps as function of time and latitude to study correlation between ion density and ion temperature. They have shown that this correlation of $\mathrm{Ni}$ and $\mathrm{Ti}$ in daytime depends on the season in the two hemispheres. There is a correlation at middle latitudes in the Southern hemisphere during solstitial seasons. In addition, they have shown during solar minimum, asymmetrical aspects of the ion density in the two hemispheres at different longitude sectors, latitudes and local times. Zhang et al. (2014b) have used an asymmetry index to reveal the electron density difference between the northern and the southern hemisphere during solstitial (December and June) and equinoctial (September and March) times. This index is calculated as function of local time, latitude and longitude. They noticed differences at higher latitudes in solar minimum year of 2009 with those in 2005-2008. They have shown that the equinoctial index during nighttime varies as the solar flux with a minimum occurring in 2009 , whereas the solstitial index has an abnormal enhancement during 2008 and 2009. Zhang et al. (2014c) have compared the electron density variation with the IRI model and the indexes F10.7 and EUV during nighttime in 2006-2008. The study of Zhang et al. (2015) is similar to the study of Zhang et al. (2014a) but for the electron density. Slominska et al. (2014) have underlined that the occurrence of the WSA and MSNA is not limited to the local summer conditions but that they are also present on the months around but with a reduced intensity. Liu et al. (2015) have studied the WSA with various satellites (Formosat-3, Tatiana-2 and DEMETER) and they have shown unusual increases (decreases) of the daytime (nighttime) electron temperature and anti-correlation between $\mathrm{Te}$ and $\mathrm{Ne}$ in the daytime and nighttime. Ryu et al. (2016) have used several ionospheric satellites (CHAMP, DEMETER, and DMSP F15) to study seasonal and spatial variations of many ionospheric anomalies including the WSA and the MSNA.

A general explanation for the mechanism generating the WSA was first given by Dudeney and Piggott (1978). They attributed the WSA to a combination of solar photoionization, thermospheric neutral winds and magnetic declination effects. Later on, this mechanism to understand these anomalies has been widely studied by, among others, Horvath (2006), Jee et al. (2009), Lee et al. (2011), Chen et al. (2011), Chang et al. (2015), and Ryu et al., (2016). In the following, some of these papers are discussed. 
Horvath (2006) noticed that the equatorward wind which is preponderant at night could carry the plasma upward at high altitudes where the recombination is slow, and then the plasma is conserved during a longer time. He has also underlined the link between the magnetic declination and the WSA with TOPEX TEC maps showing that the western boundary of the WSA is limited by contours of magnetic declination.

Jee et al. (2009) as Horvath (2006) considered that the evolution of the WSA at night can be associated with the neutral wind effects on the plasma transport along the magnetic field lines. They considered that the plasma transport by both the seasonal meridional and the diurnal zonal components of the neutral winds can have a vertical component which affects the plasma density. They summed up the effect of the meridional wind with the inclination and the effect of the zonal wind with the declination (their Figure 5). They showed that the longitudinal variations of the neutral wind effect are smaller in the Northern hemisphere due to the relatively small longitudinal variations of the inclination and declination. But in the Southern hemisphere they are very significant, and the total wind effect exactly peaks at the longitude where the WSA is observed.

With the help of the SAMI2 model, Chen et al. (2011) have shown that an equatorward neutral wind can be considered as the major cause of the WSA, while the downward flux from the plasmasphere provides an additional plasma source to increase the density.

Measurements with several satellites have been compared by Ryu et al. (2016) with ionospheric models (the IGRF Geomagnetic field model and the TIE-GCM neutral wind simulation code). They claimed that the nighttime Ne enhancement is related to the equatorward meridional wind (a typical nighttime thermospheric wind) and its combination with the seasonal wind blowing from the summer to winter hemisphere. They attributed the difference between the WSA and the MSNA to the geomagnetic field which is not aligned with the geographic poles. This confirms the results of Jee et al. (2009).

In this experimental paper a new study of the WSA and MSNA is done with DEMETER ion density data as function of the F10.7 solar flux index. F10.7 is a daily index provided by NOAA which measures the solar radio emission at a wavelength of $10.7 \mathrm{~cm}$ at the Earth's orbit (Tapping, 2013). The solar cycle 23 was unusually long and this solar radio emission at the end of 2008 was at the lowest levels since satellites have been launched. Section 2 will briefly describe the satellite DEMETER and its experiment to measure the ion density. The evolutions of the WSA and of the MSNA are shown in Section 3. Discussions are in section 4 whereas conclusions are given in Section 5.

\section{The satellite DEMETER}

DEMETER was a micro-satellite in operation between June 2004 and December 2010. Its orbit was circular, polar, and nearly sun-synchronous (10.30 LT and $22.30 \mathrm{LT})$. From the launch until December 2005 the altitude was $710 \mathrm{~km}$ and then it has been decreased to $660 \mathrm{~km}$ to avoid collision with other satellites. In the following this small altitude change will not be taken into account. Its payload allows measuring waves in different frequency ranges and also some important plasma parameters (ion composition, electron density and temperature, energetic particles). The on-board experiment IAP (Instrument Analyseur de Plasma) measured the ion density in situ with a time 
resolution of $4 \mathrm{~s}$ in the survey mode and $1 \mathrm{~s}$ in the burst mode (Berthelier et al., 2006). The registration of the density was almost continuous around the Earth except close to the auroral zones (invariant latitude $>65^{\circ}$ ). There are small gaps in the data when the on-board memory was full or when the satellite was in safe mode. The largest gap is between 27 September 2005 and 19 October 2005 when the satellite was used for technical purposes. All these data gaps do not affect the following analysis where calculations of average of ion density values are done over a long time.

DEMETER which performed measurements at $22.30 \mathrm{LT}$ is well suited to study the WSA because this anomaly appears as an electron density increase peaking between 2200 LT and local midnight (Horvath, 2006).

\section{The evolution of the anomalies}

Figure 1 displays the ion global distribution maps for the period from November 2005 to February 2006 in panel (A) and for the period from May 2005 to August 2005 in panel (B). The positions of the two anomalies used in this work are indicated, and it can be seen that they do not exactly correspond to the locations where the ion density is maximum. This is due to the fact that the work of Slominska et al. (2014) is used to exactly determine at 22.30 LT the location where the anomalies are maximum at the DEMETER altitude. They have employed a normalized density difference index in order to accurately determine their locations. Afterwards, the position where the WSA is maximum is estimated to be in a rectangle delimited in geographical longitude between $125^{\circ} \mathrm{E}$ and $-75^{\circ} \mathrm{E}$ and in geographical latitude between $-50^{\circ} \mathrm{S}$ and $-60^{\circ} \mathrm{S}$, whereas the position of the maximum of the MSNA is mainly over Japan (see also Thampi et al., 2009) between $40^{\circ} \mathrm{N}$ and $50^{\circ} \mathrm{N}$ in geographical latitude and $130^{\circ} \mathrm{E}$ and $170^{\circ} \mathrm{E}$ in geographical longitude (see Figure 1). It must be noticed that the location where the WSA is maximum is in fact far from the Weddell Sea area as it was already observed in several previous papers (see for example, Horvath and Essex, 2003). There is another MSNA in the northern Atlantic Ocean which will not be considered here because it is not so important (at least at the DEMETER altitude).

Nighttime data at 22.30 LT have been used in this study but in order to only survey the global variation of these ionospheric anomalies, ion density values when the Kp index is larger than 3 have been removed from the data set. Then data recorded during magnetic storms are avoided.

The ion density values registered in the rectangle which delimits the WSA in Figure 1A have been averaged month by month during the satellite mission. The black line in Figure 2 represents this WSA variation between August 2004 and December 2010. Figure 2 also displays the monthly variation of the F10.7 index (red line) together with its fitting curve (blue line) obtained by a least mean squared method. One can see the maxima of the ion density which mainly occur in December each year as expected from the previous studies (see section 1 ). They decrease with the values of the F10.7 index until 2009.

Figure 3 is similar to Figure 2 but for the MNSA over the northeast Asian region. It can be seen that the maxima of the averaged ion density occur in June every year as expected. They also follow the variation of the F10.7 index and decrease until 2008. However the ion density is globally lower in the MNSA than in the WSA. 
To check the extension of the two anomalies during the other months, Figure 4 displays year by year the averaged ion densities shown in Figures 2 and 3 as function of the months. It is observed for the WSA that this extension decreases during the second part of the solar cycle 23 in order to reach a minimum in 2008 and 2009, whereas for the MSNA the variation of the anomaly extension over the other months is smaller.

\section{Discussions}

The MSNA in the Northern hemisphere is considered as the counterpart of the WSA in the Southern hemisphere. But Jee et al (2009) have shown that the mechanism which induces these phenomena is more efficient for the WSA. As the WSA can be ascribed to the effect of the neutral wind on the upward plasma transport, they demonstrate that the longitudinal variation of this neutral wind is smaller in the Northern hemisphere (see introduction). This point is well confirmed by our observations. In Figures 2 and 3 it can be seen that the maximum density for the WSA in December 2005 is $3 \times 10^{4} \mathrm{~cm}^{-3}$ whereas it is $1.8 \times 10^{4} \mathrm{~cm}^{-3}$ in June 2005 for the MSNA. Considering the solar activity fall between June and December 2005, one can say that the density in the WSA is at least twice the density in the MSNA. This is in agreement with Ryu et al. (2016) who have already noticed with multi-satellite data that the WSA region involves more dynamic plasma upward drift process compared with the MSNA. In fact, it is more dynamic because they have shown that below DEMETER, in the nightside, the density of WSA region during the northern hemispheric winter is larger than the density of the MSNA region during the northern hemispheric summer, and then, the upward transport of the plasma along the magnetic field lines is more important for the WSA than for the MSNA.

The evolution of the WSA as function of the months complies with Jee et al. (2009) who noticed that the WSA appears only in summer when F10.7 is low, but in all seasons (except in winter) when F10.7 is high.

In order to quantify the relative variation of the ion density in the WSA with the F10.7 index variation, the ratio between the averaged values in December each year and the averaged value in December 2004 has been calculated (December being the month where the WSA is maximum). Using the fitting curve shown in Figure 2, the ratio between the averaged F10.7 value in December each year and the averaged F10.7 value in December 2004 have been also calculated. These two ratios are shown in the top panel of Figure 5. The same process has been done for the MSNA but the reference month is now June 2005 (June being the month where the MSNA is maximum) and the two corresponding curves are displayed in the bottom panel of Figure 5. One can see that the relative decrease of the density at the end of the solar cycle is more important that the relative decrease of the F10.7 index and much more important for the WSA than for the MSNA. This implies that the density variation in the anomalies is not linearly proportional to the solar flux index F10.7 and that the uplifting processes which increase the density in the topside ionosphere are not efficient when the density is low.

As it was noticed by Horvath (2006) the solar ionization could be active at high latitudes in local summer even during nighttime and, then, it reinforces the anomalies. This has been checked with the DEMETER satellite and Figure 6 shows the location of the sunshine limits at high latitudes during nighttime on the Earth's map. Figure $6 \mathrm{~A}$ is related to the sunshine in June (summer in the Northern hemisphere) whereas Figure $6 \mathrm{~B}$ is related to the sunshine in December (summer in the Southern hemisphere). The two maps in geographical coordinates show grey areas where data are 
recorded at 22.30 LT but only when the sun is not shining on the satellite. This information is issued from a housekeeping parameter given by the satellite concerning its solar panel. One clearly sees the limits close to $36^{\circ} \mathrm{N}$ in the Northern hemisphere and close to $40^{\circ} \mathrm{S}$ in the Southern hemisphere. Apart from the seasons, these latitudinal limits of course depend on the altitude of the satellite and on the local time. It can be seen that, during nighttime $(22.30 \mathrm{LT})$ at the altitude of the satellite $(660 \mathrm{~km})$, the sun is shining on the WSA region in December as well as on the MSNA region in June. Moreover the sun shining limit of the MSNA is close to the limit where the anomaly is maximum whereas there is an extension of $10^{\circ}$ for the WSA. It means that the contribution of the solar ionization is far to be negligible for the two anomalies, and is more important for the WSA because it lasts much longer.

A last point is that many different assumptions can be given depending on the devices employed to study these anomalies because an important parameter is the altitude at which the investigations are done. For example, Chen et al. (2012) presented the long-term variations of the MSNA in the two hemispheres by using NmF2 values extracted from a network of ground-based ionospheric sounders between 1957 and 2010 (i.e. they worked with data measured at an altitude about $250 \mathrm{~km}$ lower than the DEMETER altitude $(660 \mathrm{~km}))$. They have observed high MSNA in the low solar activity condition and low MSNA in the high solar activity condition. Similarly, Liu et al. (2010) with density data measured at $400 \mathrm{~km}$ by the CHAMP satellite found that the MSNA is more pronounced at solar minimum than at solar maximum. These two observations are exactly the opposite of the observations shown in our paper. It also means that the studies using TEC which totally integrates the ionosphere over the altitude must be cautiously considered.

\section{Conclusions}

The ion density data recorded by the low-altitude satellite DEMETER have been used to survey in nighttime (22.30 LT) the variations of the WSA and of the MSNA over the northeast Asian region during the declining phase of the solar cycle 23. Although the MSNA is regarded as the northern hemispheric conjugate phenomenon of the WSA several differences have been underlined. Our results indicate that among the physical processes that are responsible for the WSA and the MSNA, the solar ionization is preponderant because the decrease of their densities follows the decrease of the solar activity. To be more specific a number of behaviors can be mentioned:

(i) The density peaks of the WSA and MSNA during the local summer decrease with the F10.7 index from 2004 to 2008 but for the WSA the anomaly extension on the other months is restricted.

(ii) This decrease is not directly proportional to the F10.7 index and is much more significant for the WSA than for the MSNA.

(iii) A key parameter is the altitude at which the measurements are performed. The solar ionization is an important factor because these WSA and MSNA areas at high latitudes are well-lit and not in night as the DEMETER local time seems to indicate.

(iv) The solar ionization at night is more important for the WSA than for the MSNA. This point together with the fact that the uplifting plasma mechanism is more efficient for the WSA could explain that we found in average a density in the WSA which is twice the density in the MSNA. 


\section{Acknowledgments}

This work is mainly related to data recorded by the ion spectrometer IAP of the micro-satellite DEMETER which was operated by the French Centre National d'Etudes Spatiales (CNES). The authors thank J.J. Berthelier the PI of IAP for the use of the data. The DEMETER data shown in this paper can be obtained at https://cdpp-archive.cnes.fr/._The F10.7 index values have been downloaded from https://celestrak.com/SpaceData/SpaceWx-format.asp thanks to NOAA. This work is supported by the National Natural Science Foundation of China (No.41404058) and special fund for public welfare of Scientific Research Project of ICD, CEA (No.ZDJ2016-19)

\section{References}

Bellchambers, W. H., and Piggott, W. R., 1958. Ionospheric measurements made at Halley Bay. Nature. 182(4649), 1596-1597, doi:10.1038/1821596a0.

Berthelier, J.J., Godefroy, M., Leblanc, F., Seran, E., Peschard, D., Gilbert, P., and Artru, J., 2006. IAP, the thermal plasma analyzer on DEMETER. Planetary and Space Science, 54(5), 487-501,

Burns, A.G., Zeng, Z., Wang, W., Lei, J., Solomon, S.C., Richmond, A.D., Killeen, T. L., and Kuo, Y.-H. , 2008. Behavior of the F2 peak ionosphere over the South Pacific at dusk during quiet summer conditions from COSMIC data. J. Geophys. Res. 113, A12305, doi:10.1029/2008JA013308.

Chang, L. C., Liu, H., Miyoshi, Y., Chen, C. H., Chang, F. Y., Lin, C. H., Liu, J.-Y., and Sun, Y. Y., 2015. Structure and origins of the Weddell Sea Anomaly from tidal and planetary wave signatures in FORMOSAT-3/COSMIC observations and GAIA GCM simulations. J. Geophys. Res. Space Phys. 120(2), 1325-1340, doi:10.1002/2014JA020752.

Chen, C. H., Huba, J. D., Saito, A., Lin, C. H., and Liu, J. Y. , 2011. Theoretical study of the ionospheric Weddell Sea Anomaly using SAMI2. J. Geophys. Res. Space Phys., 116, A04305, doi:10.1029/2010JA015573

Chen, C.H., Saito, A., Lin, C. H., Liu, J. Y., 2012. Long-term variations of nighttime electron density enhancement during the ionospheric midlatitude summer. J. Geophys. Res. Space Phys., 117, A07313, doi:10.1029/2011JA017138.

Dudeney, J. R., and Piggott, W.R, 1978. Antarctic ionospheric research. Upper Atmosphere Research in Antarctica. 29, edited by L. J. Lanzerotti and C. G. Park, pp. 200-235, AGU, Washington, D. C., doi:10.1029/AR029p0200.

Horvath, I., 2006. A total electron content space weather study of the nighttime Weddell Sea Anomaly of 1996/1997 southern summer with TOPEX/Poseidon radar altimetry. J. Geophys. Res. Space Phys. 111,A12, doi:10.1029/2006JA011679.

Horvath, I., and Essex, E. A., 2003. The Weddell Sea Anomaly observed with the Topex satellite data. Journal of atmospheric and solar-terrestrial physics, 65(6), 693-706.

Horvath, I., and Lovell, B. C., 2009. Investigating the relationships among the South Atlantic magnetic anomaly, southern nighttime midlatitude trough, and nighttime Weddell Sea anomaly during southern summer. J. Geophys. Res. Space Phys. 114, A02306, doi:10.1029/2008JA013719. 
He, M., Liu, L., Wan, W., Ning, B., Zhao, B., Wen, J., Yue, X., and Le, H., 2009. A study of the Weddell Sea Anomaly observed by FORMOSAT-3/COSMIC, J. Geophys. Res. Space Phys. 114, A12309, doi:10.1029/2009JA014175.

Jee, G., Burns, A. G., Kim, Y. H., \& Wang, W., 2009. Seasonal and solar activity variations of the Weddell Sea Anomaly observed in the TOPEX total electron content measurements. J. Geophys. Res. Space Phys., 114, A04307, doi:10.1029/2008JA013801.

Lee, W. K., H. Kil, Y. S. Kwak, Q. Wu, S. Cho, and J. U. Park, 2011. The winter anomaly in the middlelatitude $\mathrm{F}$ region during the solar minimum period observed by the Constellation Observing System for Meteorology, lonosphere, and Climate, J. Geophys. Res. Space Phys. 116, A02302, doi:10.1029/2010JA015815.

Li, L. Y., Yang, J.-Y., Cao, J. B., Lu, L., Wu, Y., Yang, D. M., 2011. Statistical backgrounds of topsideionospheric electron density and temperature and their variations during geomagnetic activity. Chinese Journal of Geophysics (Chinese Edition), 54(10):2437-2444, doi:10.3969/j.issn.00015733.2011.10.001.

Lin, C. H., Liu, J. Y., Cheng, C. Z., Chen, C. H., Liu, C. H., Wang, W. , Burns, A. G., and Lei, J., 2009. Three-dimensional ionospheric electron density structure of the Weddell Sea Anomaly, J. Geophys. Res. Space Phys. 114, A02312, doi:10.1029/2008JA013455.

Lin, C. H., Liu, C. H., Liu, J. Y. , Chen, C. H. ,Burns, A. G., and Wang, W., 2010. Midlatitude Summer Nighttime Anomaly of the ionospheric electron density observed by FORMOSAT-3/COSMIC. J. Geophys. Res. Space Phys., 115, A03308, doi:10.1029/2009JA014084.

Liu, H., Thampi, S. V., and Yamamoto, M., 2010. Phase reversal of the diurnal cycle in the midlatitude ionosphere. J. Geophys. Res. Space Phys. 115, A01305, doi:10.1029/2009JA014689.

Liu, J. Y., Chang, F. Y., Oyama, K. I., Kakinami, Y., Yeh, H. C., Yeh, T. L. , Jiang, S. B., and Parrot, M., 2015. Topside ionospheric electron temperature and density along the Weddell Sea latitude. J. Geophys. Res. Space Phys., 120, 609-614 doi:10.1002/2014JA020227.

Lühr, H., and Xiong, C., 2010. IRI-2007 model overestimates electron density during the 23/24 solar minimum. Geophys. Res. Lett., 37, L23101, doi:10.1029/2010GL045430.

Ryu, K., Kwak, Y., Kim, Y. H., Park, J., Lee, J., and Min, K., 2016 . Variation of the topside ionosphere during the last solar minimum period studied with multi-satellite measurements of electron density and temperature. J. Geophys. Res. Space Phys. 121, 7269-7286, doi:10.1002/2015JA022317.

Slominska, E., Blecki, J., Lebreton,J. P., Parrot, M., and Slominski, J. ,2014. Seasonal trends of nighttime plasma density enhancements in the topside ionosphere. J. Geophys. Res. Space Phys. 119, 6902-6912, doi:10.1002/2014JA020181.

Tapping, K. F., 2013. The $10.7 \mathrm{~cm}$ solar radio flux (F10.7). Space Weather, 11, 394-406, doi:10.1002/swe.20064.

Thampi, S. V., Lin, C., Liu, H., and Yamamoto, M., 2009 .First tomographic observations of the Midlatitude Summer Nighttime Anomaly over Japan. J. Geophys. Res. Space Phys. 114, A10318, doi:10.1029/2009JA014439. 
Zhang, X., 2014. Electron density comparison between IRI 2007 and DEMETER satellite data in solar minimum year. Terr. Atmos. Ocean. Sci. 25(4), 559-571, doi: 10.3319/TAO.2014.02.24.01(AA).

Zhang, X., Shen, X., Liu, J., Zeren, Z., Yao, L., Ouyang, X., Zhao, S., Yuan, G. and Qian, J., 2014a. The solar cycle variation of plasma parameters in equatorial and mid latitudinal areas during 2005-2010. Advances in Space Research, 54(3), 306-319.

Zhang, X., Shen, X., Liu, J., Yao, L., Yuan, G., and Huang, J., 2014b. The asymmetrical features in electron density during extreme solar minimum. Advances in Space Research. 54(11), 2236-2248.

Zhang, X., Qian, J., and Shen, X., 2014c. Solar cycle variation of the electron density in the topside ionosphere at local nighttime observed by DEMETER during 2006-2008. J. Geophys. Res. Space Phys. 119,3803-3814 doi: 10.1002/2013JA019463.

Zhang, X., Shen, X., and Yuan, G., 2015. The solar cycle variations of plasma parameters and their correlations at topside ionosphere from DEMETER during 2005-2010. Advances in Space Research, 56(7), 1374-1388.

\section{Legends of Figures}

Figure 1: Map showing the ion global distribution for the period from November 2005 to February 2006 in panel (A) and for the period from May 2005 to August 2005 in panel (B). The ion density is color-coded according to the scale on the right. The positions of the two anomalies considered in this paper are indicated (see text).

Figure 2: Monthly variations of the ion density in the WSA between August 2004 and December 2010 (black line). The red line represents the monthly variations of the F10.7 index and the blue line is the fitting curve of the red line.

Figure 3: Same as Figure 2 but for the MSNA.

Figure 4: Averaged densities recorded in WSA (top panel) and in MSNA (bottom panel) areas as a function of the months during several years. For each year the corresponding curve is color-coded according to the insert in the right top corner of the panels.

Figure 5: The black lines represent the relative variation of the ion density for the WSA (top panel) and for the MSNA (bottom panel) as function of the years. The red lines concern the relative variation of the F10.7 index (see text for explanation).

Figure 6: Global maps showing in grey the areas where the scientific payload is $\mathrm{ON}$ and the satellite is in the shadow of the Earth in June (panel A) and in December (panel B) at 22.30 LT (the complete area where data are recorded is shown in Figure 1). 

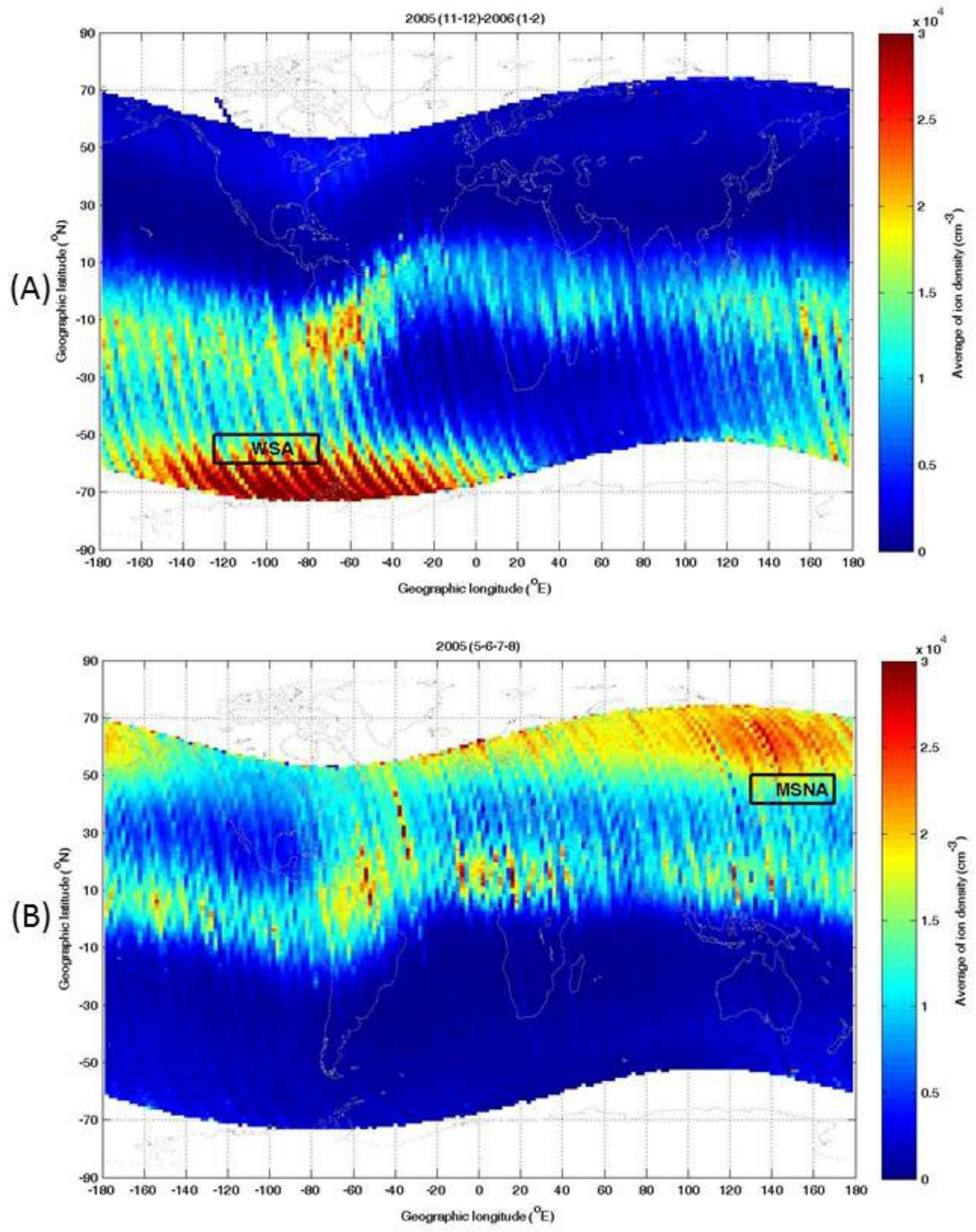



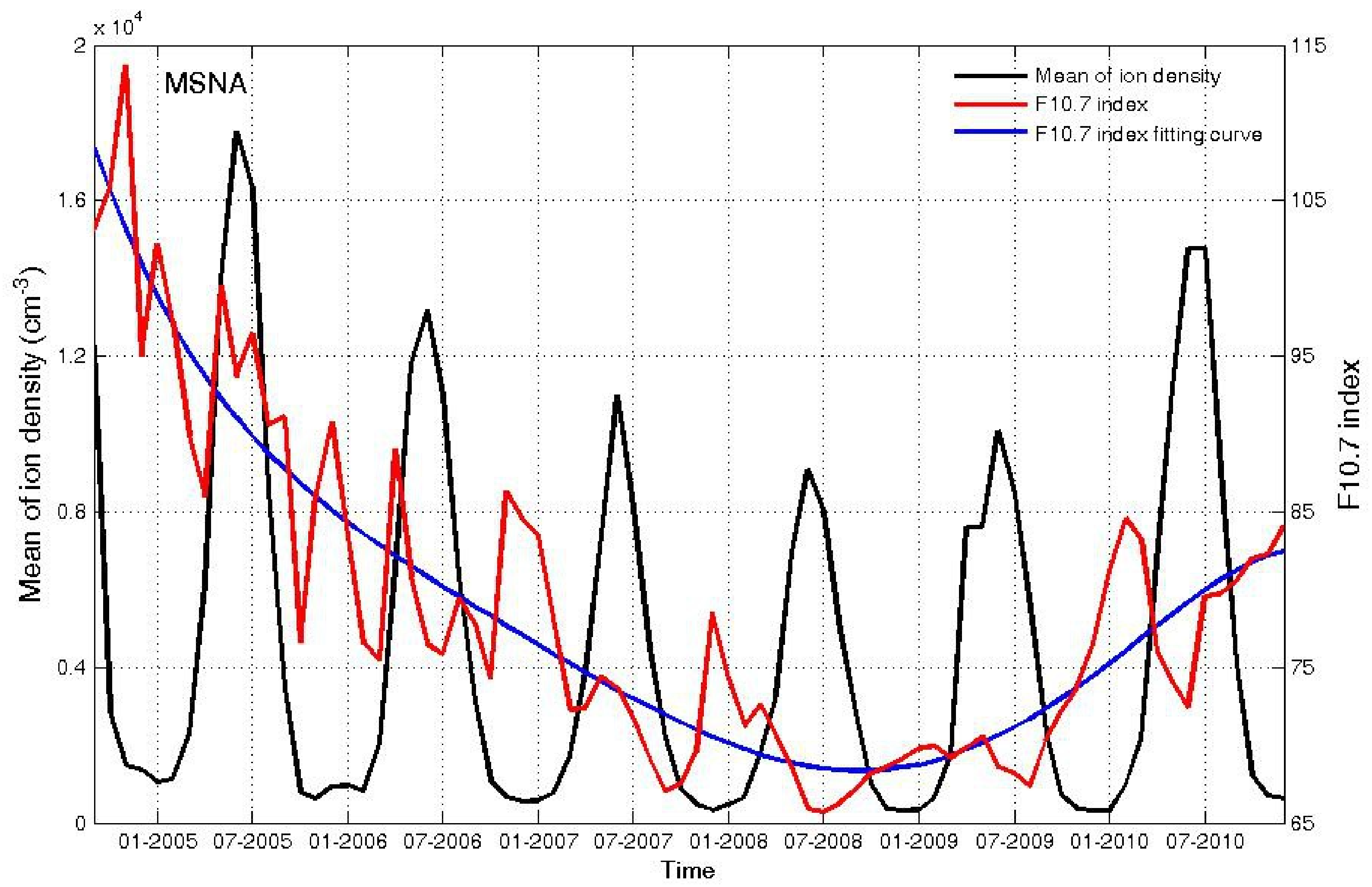



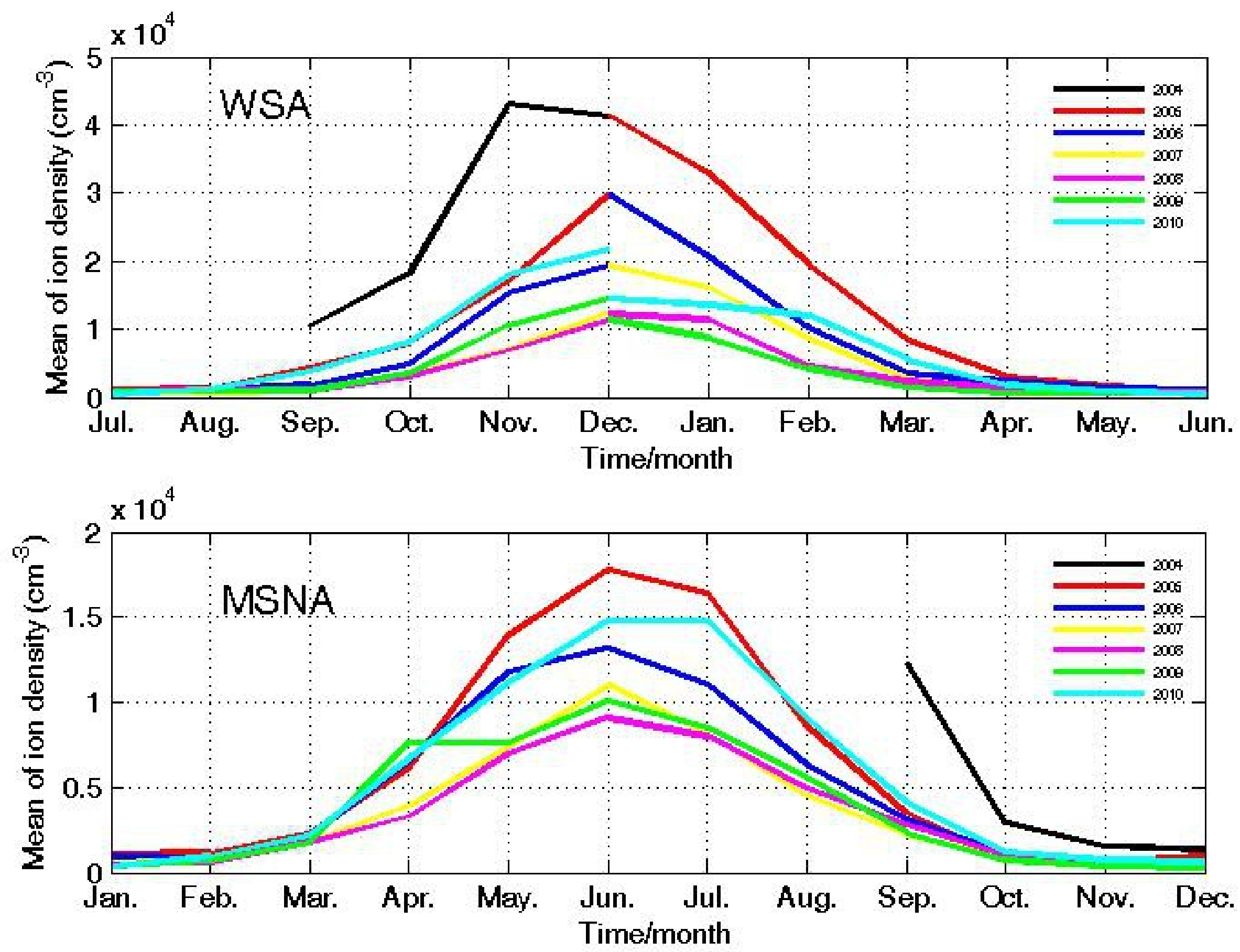

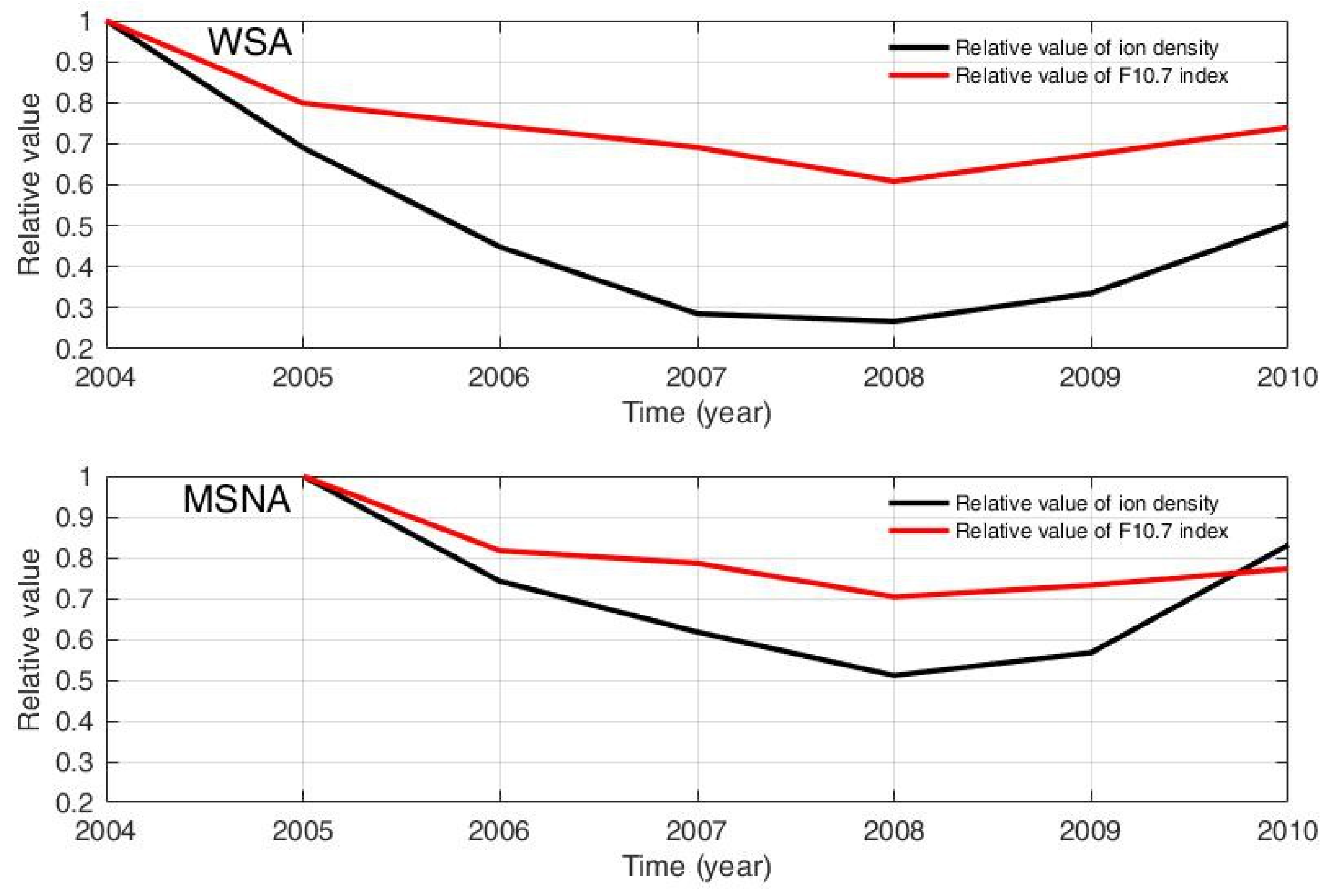

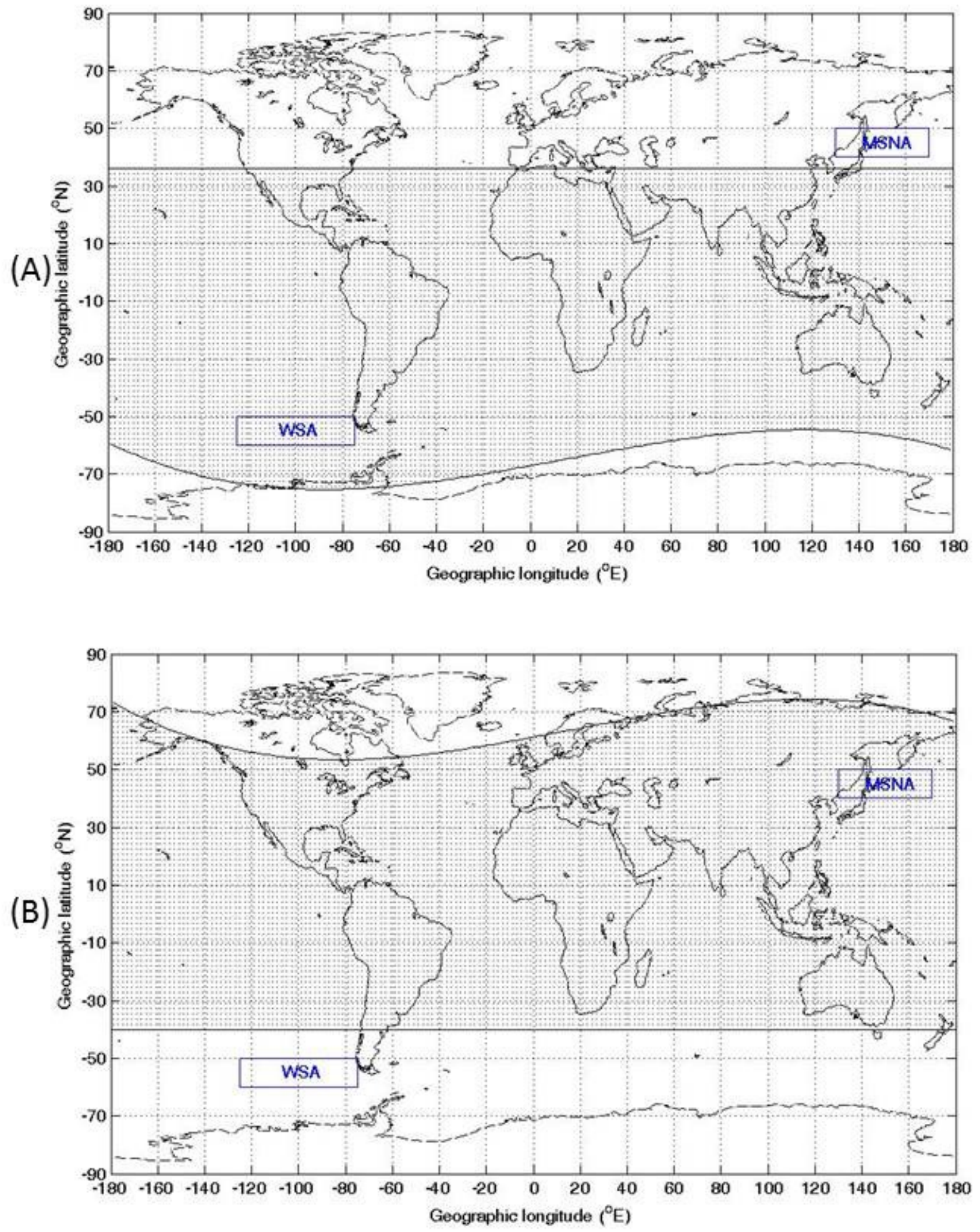